Contract No. and Disclaimer:

This manuscript has been authored by Savannah River Nuclear Solutions, LLC under Contract No. DE-AC09-08SR22470 with the U.S. Department of Energy. The United States Government retains and the publisher, by accepting this article for publication, acknowledges that the United States Government retains a non-exclusive, paid-up, irrevocable, worldwide license to publish or reproduce the published form of this work, or allow others to do so, for United States Government purposes. 
SRNL-STI-2010-00461

\title{
Crush Testing of 9977 General Purpose Fissile Packagings
}

\author{
A. C. Smith \\ Savannah River National Laboratory \\ Savannah River Nuclear Solutions \\ Aiken, South Carolina 29808 \\ (803) 725 2943, \\ allen.smith@snl.doe.gov
}

\begin{abstract}
The 9977 General Purpose Fissile Package (GPFP) was designed in response to the adoption of the crush test requirement in the US regulations for packages for radioactive materials (10 CFR 71). This presentation on crush testing of the 9977 GPFP Reviews origins of Crush Test Requirements and implementation of crush test requirements in 10 CFR 71. SANDIA testing performed to support the rule making is reviewed. The differences in practice, on the part of the US Department of Energy from those required by the NRC for commercial purposes, are explained. The design features incorporated into the 9977 GPFP to enable it to withstand the crush test and the crush tests performed on the 9977 are described. Lessons learned from crush testing of GPFP packagings are given.
\end{abstract}

\section{Background}

In March, 1941, Emilio Segre and Glenn Seaborg irradiated $1.2 \mathrm{~kg}$ of uranium in the University of California, Berkley cyclotron to produce a small amount of element 93. The bombardment activated the target material, yielding fission products from neutron bombardment along with the new element. Segre and Seaborg recognized the hazard of the activated specimen and placed it into a lead bucket and carried it on a long pole across the street to the Chemistry building for separation of the new element from the remainder of the specimen. They wore lead gloves and goggles for the operation. They had a short distance to carry the specimen, employed a shielded container and remote handling and personal protective equipment to minimize their exposure.

It was recognized by all in the industry, from the earliest days, that radioactive materials required special handling to avoid possible exposure of the workers and public to the hazards of radiation and contamination. The need for suitable packaging for containment and transport of these materials led to early development of simple containment vessel and overpack type packages. Whether these were adequately robust was an important concern. Experiments to determine the loads imparted to packages in transportation accidents were performed to provide a basis for evaluating package performance.

\section{Early Tests of RAM Packaging}

Important early tests were conducted at Aberdeen Proving Grounds, in the United States and MIRA facility in the United Kingdom. In these tests, remotely operated vehicles, loaded with a variety of packages, were driven into barricades. The resulting damage to the packages was evaluated to determine loads imparted to the packages and the response of various package configurations to them. These early tests showed that the packages 
were subjected to a variety of mechanical loads. These can be grouped into three categories, impact, crush and penetration.

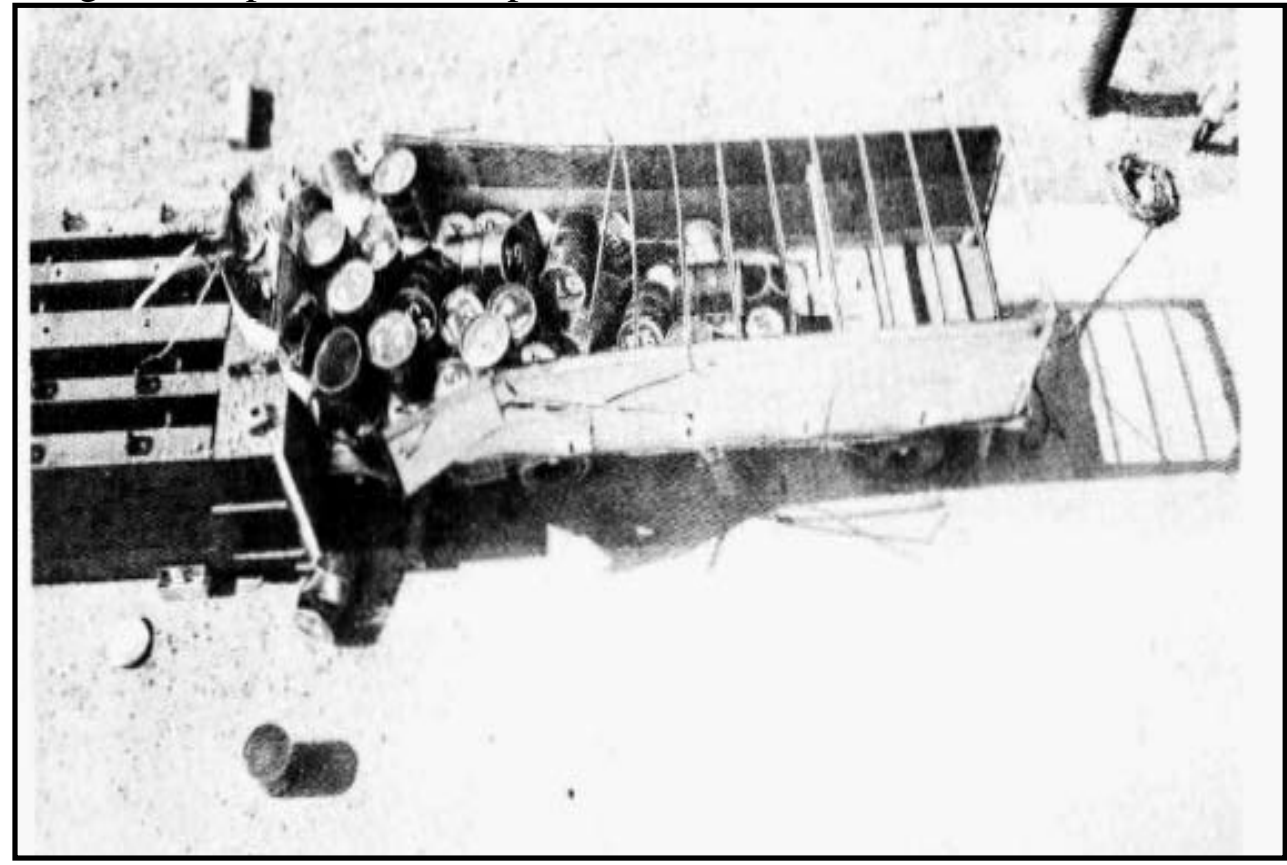

Figure 1. Aberdeen Proving Ground Test, 1966. Illustrations from "Early Accidentsimulating Testing of Radioactive Material Packages in Road Vehicles”, R. B. Pope, L. B. Shappert, C. Taylor and R. A. Vaughan, Proceedings of the 15th International Symposium on Packaging and Transportation of Radioactive Material. PATRAM 2007, October 2007.

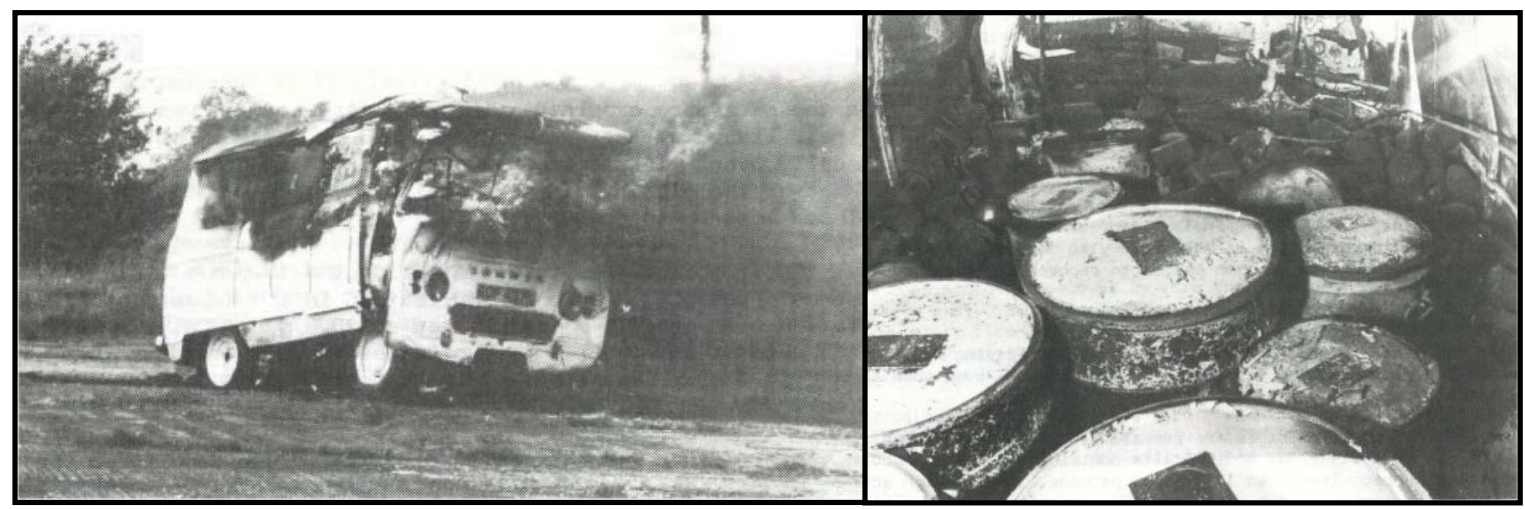

Figure 2. Testing at MIRA facility in UK (Vehicle B)

For large packages, such as casks for fuel and components, or for very robust small packages, the impact and penetrations challenges are most challenging. Light, low density packages are susceptible to crush loads. However, they are relatively less vulnerable to impact loads. The advisory material for International Atomic Energy Agency, Regulations for Safe Transport of Radioactive Materials (TS-R-1), notes that accident analyses have indicted that the probability of dynamic crush loading for small packages is greater than for impact. In addition, handling and storage mishaps may lead 
to undue static or dynamic crush loads. In recognition of this, 1985 edition of the IAEA Regulations included a crush test requirement for relatively light packages containing significant amounts of radioactive material. This requirement applies to packages having a mass not greater than $500 \mathrm{~kg}$, an overall density not greater than $1000 \mathrm{~kg} / \mathrm{m}^{3}$ and radioactive contents greater than $1000 \mathrm{~A}_{2}$, not as special form. The crush test is specified in lieu of the $9 \mathrm{~m}$ drop test.

\section{SANDIA Crush Test Program}

In the development of the regulation, the absence of data on package response to crush events was a concern for the technical groups responsible for developing the appropriate test requirements. In response to this need a test program was conducted at Sandia National Laboratory to evaluate the response of small Type B packagings to crush tests using the proposed rules (impact by a $1 \mathrm{~m}$ square, $500 \mathrm{~kg}$ plate dropped from $9 \mathrm{~m}$ ). The testing included a variety of contemporary packagings, including the DOT 6M Specification Package, the Rocky Flats Bird Cage and the Y-12 Model 9B.

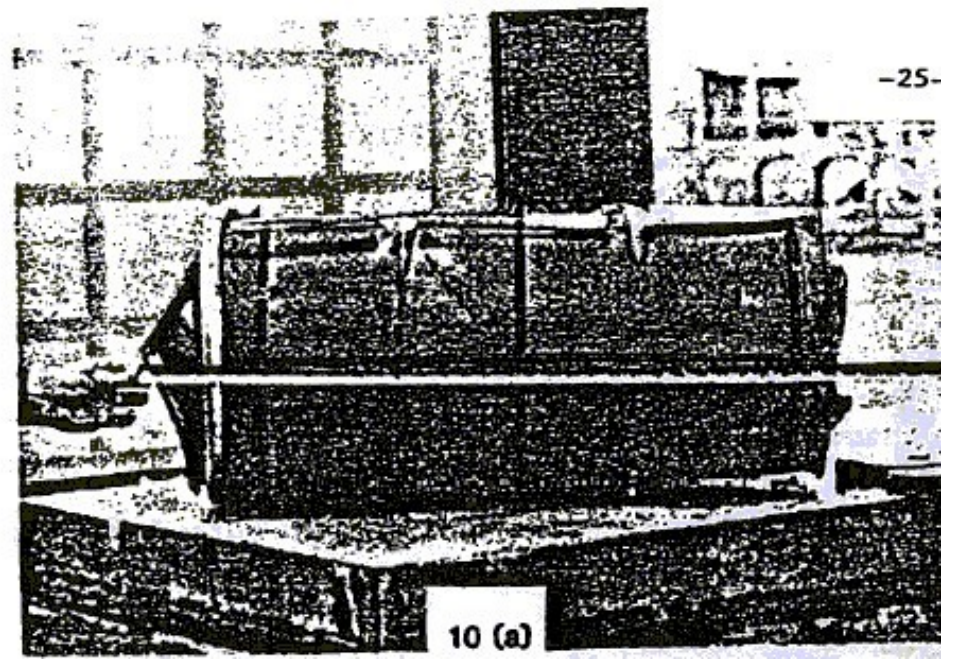

Figure 3. 30 gal Generic Package (6M)

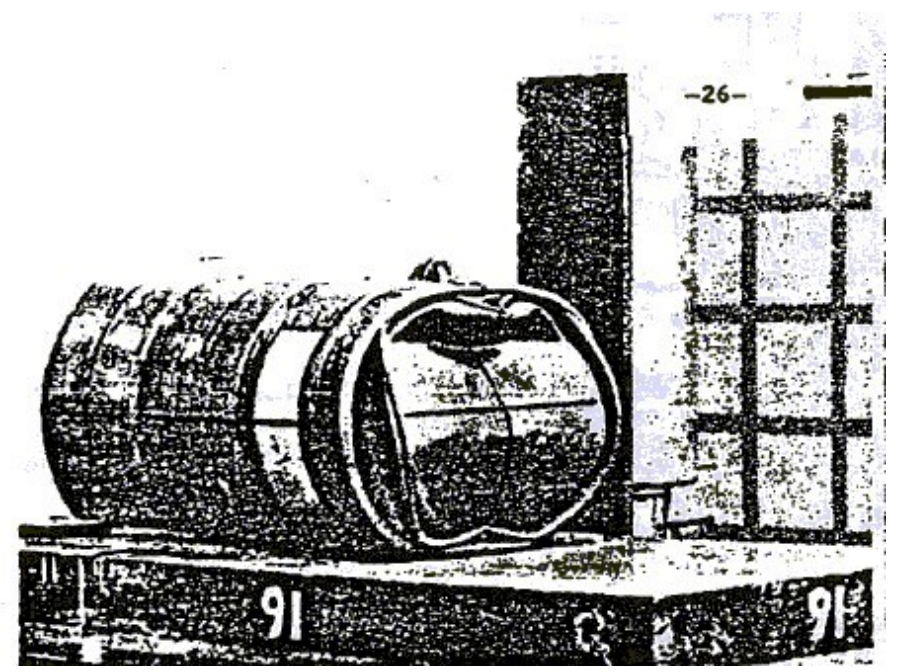

Figure 4. 55 gal Generic Package (6M) 


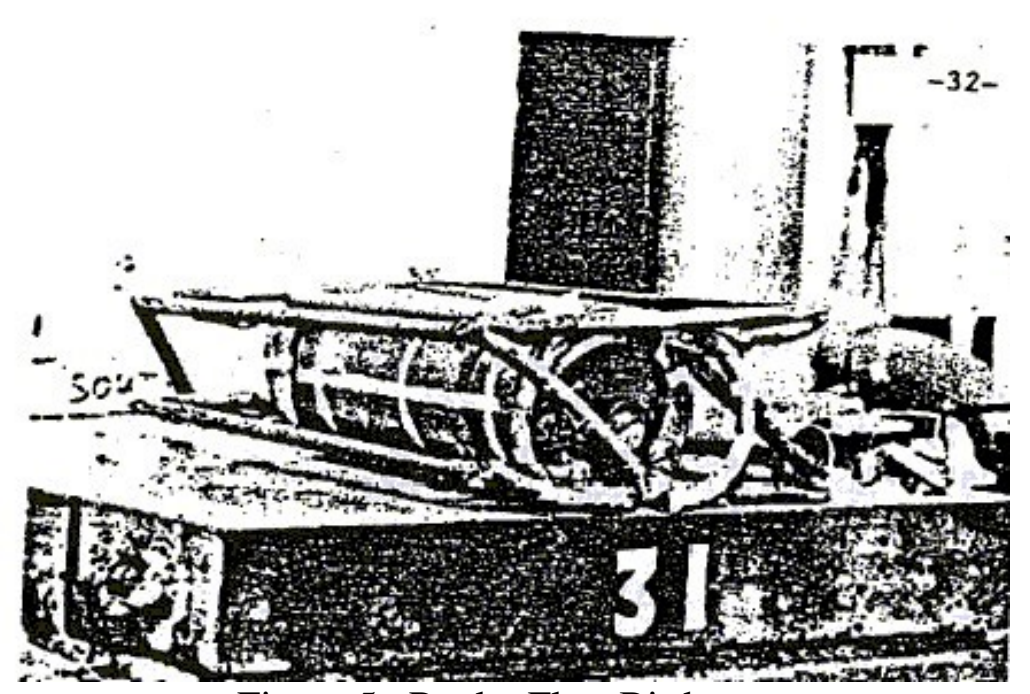

Figure 5. Rocky Flats Birdcage

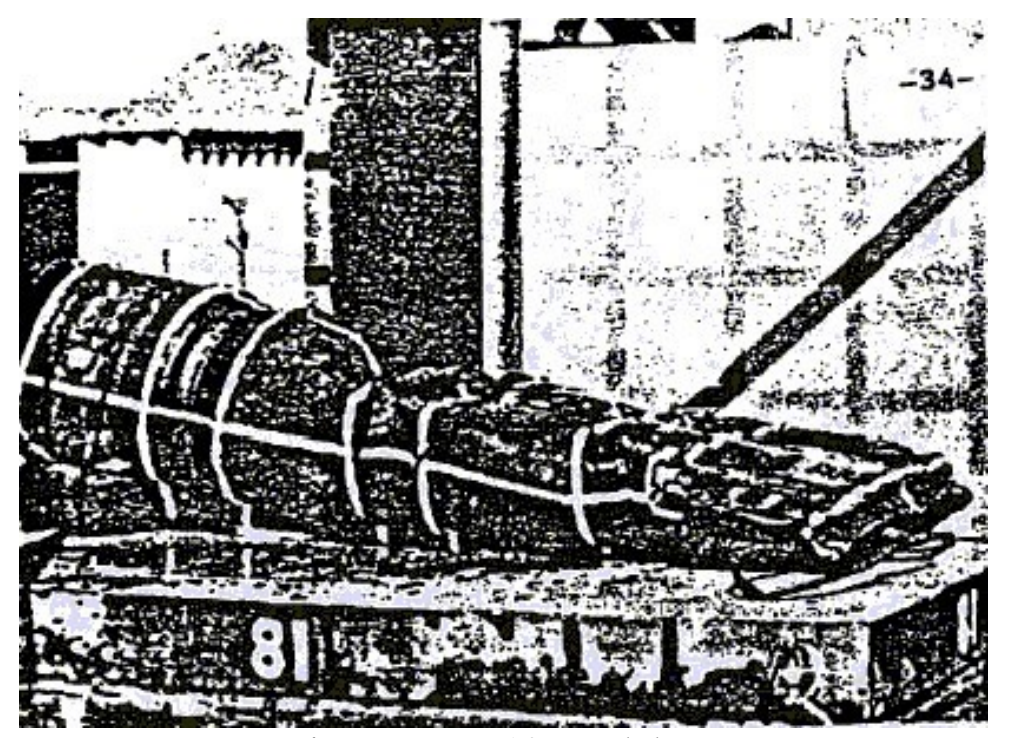

Figure 6. Y-12 Model 9B

The results of the tests showed that the crush test was a severe challenge to small, lightweight packagings. The crush impact typically resulted in opening of the outer container and exposure of the impact absorbing and thermal insulating overpack material. This would have compromised the ability of the overpack material to withstand a subsequent fire test. In addition, the deformation was sufficient that significant loads were transmitted to the containment vessels.

Implementation of the Crush Test in 10 CFR 71

The US Nuclear Regulatory Commission (NRC) implemented the Crush Test requirement as 10 CFR 71.73(c)(2) in the 1995 revision to the regulation. In the commentary on the rule change, the NRC said: 
NRC believes that the crush test and the free drop test impart different types of loadings onto the package. Having sufficient crush resistance for the crush test does not insure adequacy of the package under the inertial loadings that occur during the 30-foot drop tests. NRC believes that it is important for packages to have resistance to impact and that the crush test should not be a substitute for the impact test.

So, the NRC requires both drop and crush tests, for packages requiring crush testing.

It is worthy of note that this is supported by the Sandia report.

As implemented in 10 CFR 71, the NRC requires the crush test for packages having a mass not greater than $500 \mathrm{~kg}$ and an overall density not greater than $1000 \mathrm{~kg} / \mathrm{m}^{3}$ based on the external dimensions, and a radioactive contents greater that $1000 \mathrm{~A}_{2}$ not as special form radioactive material. This is the same as the IAEA basis.

It should also be noted that the NRC allows appropriate analyses to be used to demonstrate the ability of the package to meet crush test conditions (Section 71.41).

\section{US Department of Energy Practice}

DOE practice requires that all packagings be able to withstand the crush test, regardless of whether they fall within the size, mass and contents limits of the regulations.

Accordingly, the test programs for the 9977 General Purpose Fissile Package (GPFP) and the ES-3100 have included crush testing. Like other parts of the Hypothetical Accident Condition (HAC) Sequential Test, the test is conducted in the orientation expected to be most challenging to the package. In the following figures (Figures 7 - 11), the test package is placed on a hard, essentially immovable surface in the test orientation. The surface is a $10 \mathrm{~cm}$. thick steel plated, secured and grouted in place on a large, reinforcedconcrete structural footer. The crush plate was a $1 \mathrm{~m}$ square, $63.5 \mathrm{~mm}$ thick plate, weighing $531 \mathrm{~kg}$. The plate was dropped from $9 \mathrm{~m}$ in the horizontal orientation, as shown in Figures 8 and 9. The test procedure for the ES-3100, Figure 12, was similar. 


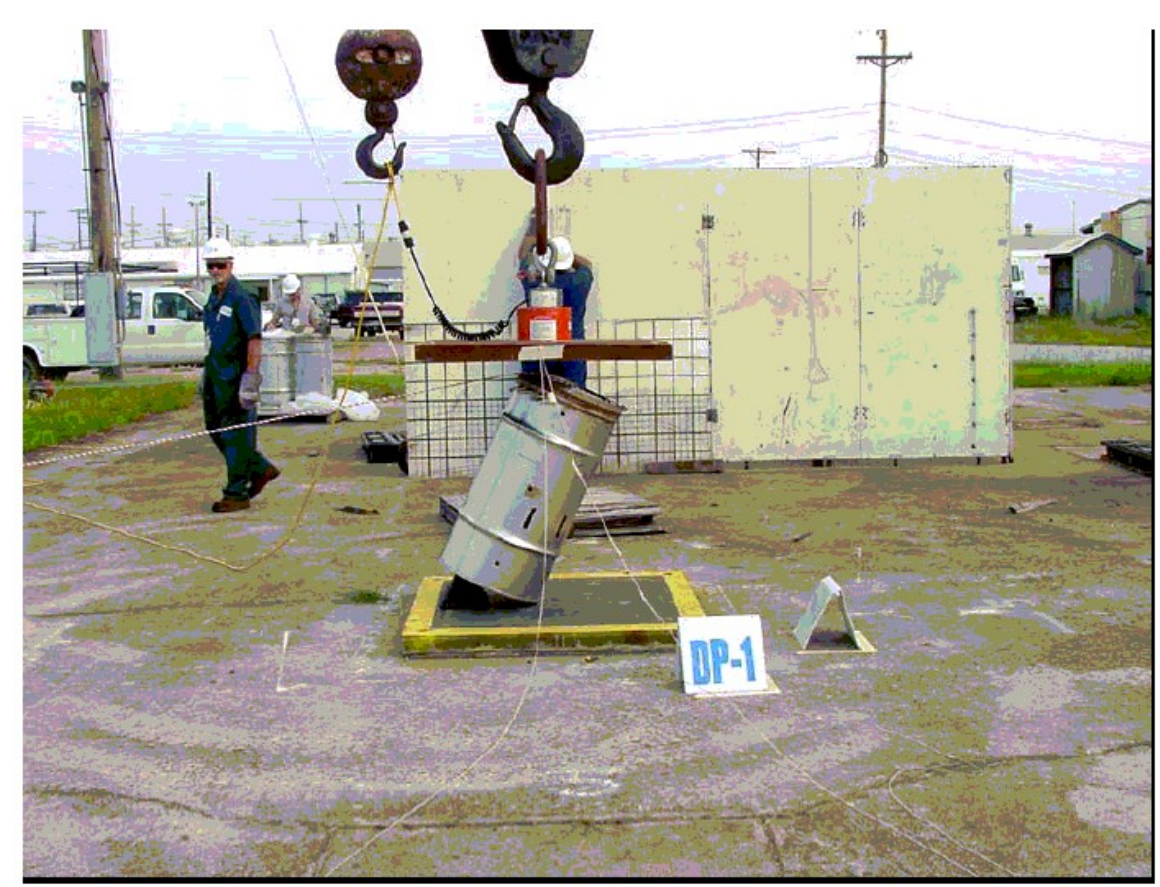

Figure 7. Crush Test of 9977 General Purpose Fissile Package (GPFP).

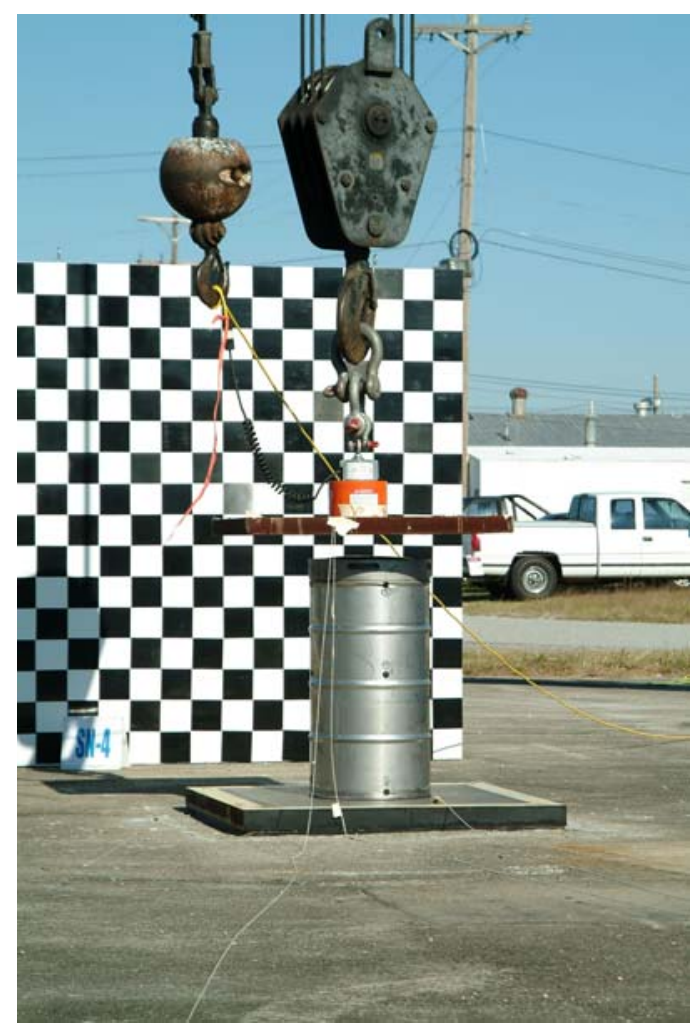

Figure 8. Rigging of the crush plate for a 9977 crush test of package in vertical orientation. 


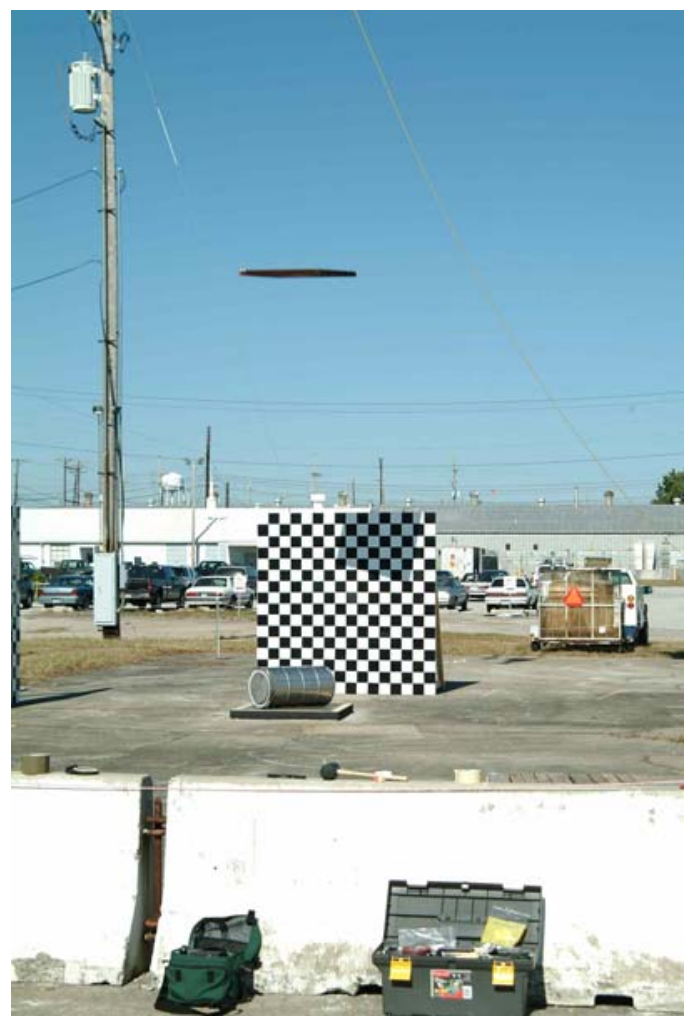

Figure 9. Crush plate falling for 9977 crush test for horizontal package orientation.

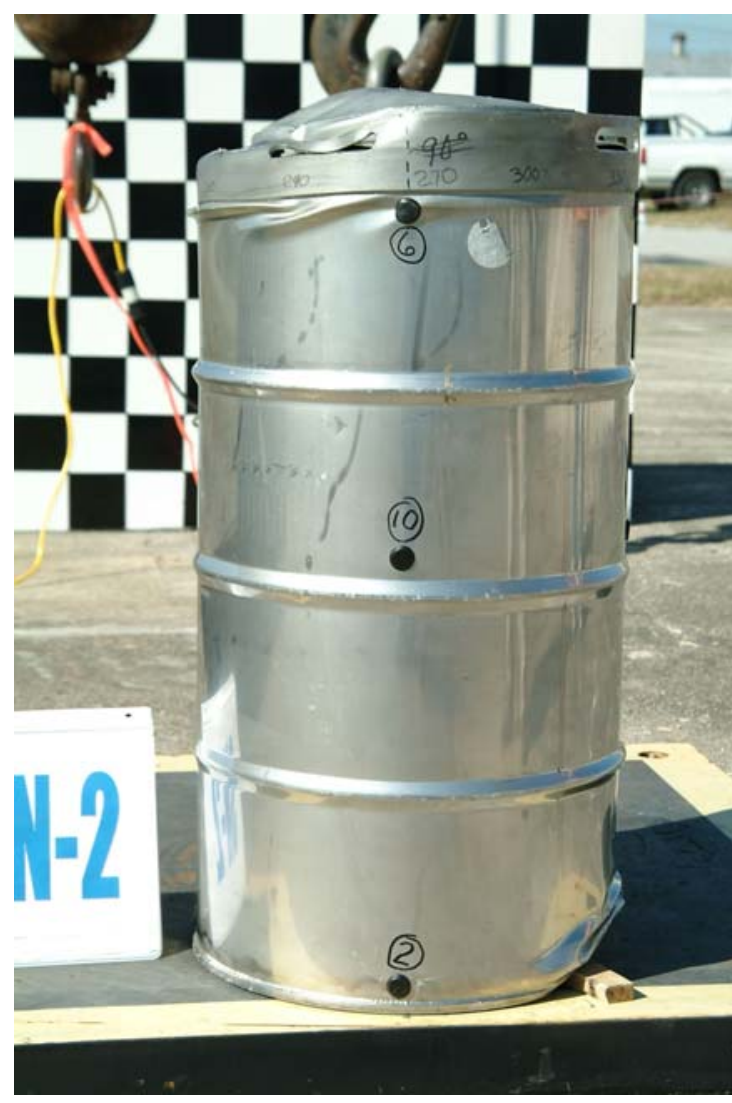


Figure 10. Damage resulting from crush test in Center of Gravity Over Corner (COGC) orientation

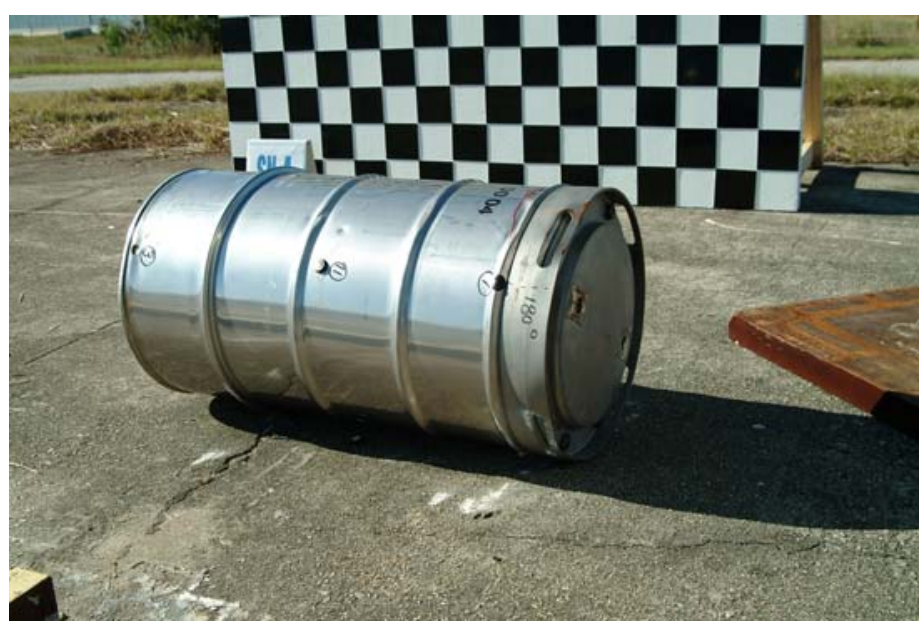

Figure 11. Damage resulting from crush test in horizontal orientation.

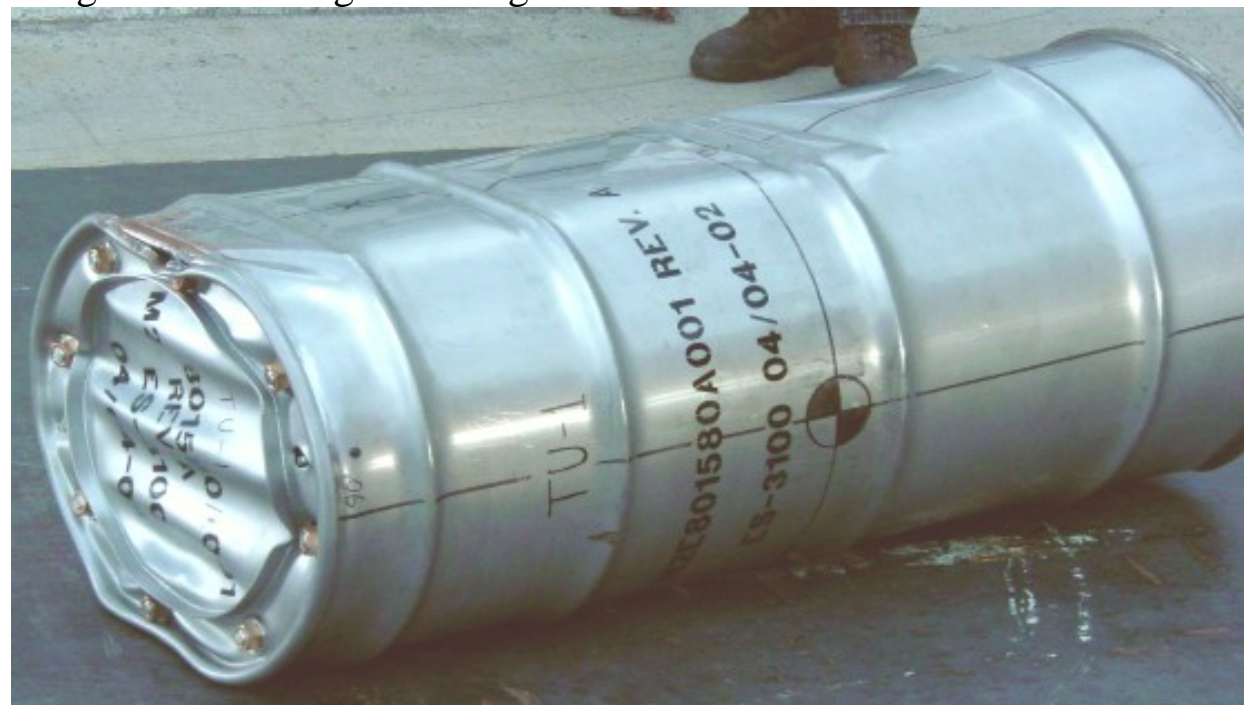

Figure 12. Damage resulting from crush test in horizontal orientation of ES-3100. (Photograph courtesy of Oak Ridge Natioinal Laboratory.)

\section{Results of Tests}

The crush tests of the 9977 and ES-3100 showed that the engineered Type B packages, successfully withstand the crush and other tests of the HAC Sequential Tests. Following the complete HAC tests sequence, the containment vessels were confirmed to be leak tight.

\section{Lessons Learned}

The crush test is a severe challenge for light-weight packagings, such as the common drum type packaging. Accordingly, the packaging must be designed to withstand the crush event. 
Appropriate design and specification of proper overpack material can result in crush resistant packagings.

Experience has shown that the response of the package to the test is a function of package design. Typically, the response of the crush plate upon impact is energetic, with significant rebound and rotation. Accordingly, a large test area surrounded by robust barricades is essential. For this reason, use of an outdoor facility is advisable.

\section{Contract Number}

This document was prepared in conjunction with work accomplished under Contract No. DE-AC09-08SR22470 with the U.S. Department of Energy.

\section{Disclaimer}

The United States Government retains, and by accepting the article for publication, the publisher acknowledges that the United States Government retains, a non-exclusive, paidup, irrevocable, worldwide license to publish or reproduce the published form of this work, or allow others to do so, for United States Government purposes.

This work was prepared under an agreement with and funded by the U.S. Government. Neither the U. S. Government or its employees, nor any of its contractors, subcontractors or their employees, makes any express or implied: 1. warranty or assumes any legal liability for the accuracy, completeness, or for the use or results of such use of any information, product, or process disclosed; or 2. representation that such use or results of such use would not infringe privately owned rights; or 3. endorsement or recommendation of any specifically identified commercial product, process, or service. Any views and opinions of authors expressed in this work do not necessarily state or reflect those of the United States Government, or its contractors, or subcontractors.

\section{References}

1. "Regulations for the Safe Transport of Radioactive Material”, IAEA Safety Standards, Safety Requirements TS-R-1, 2005.

2. United States Code of Federal Regulations, Part 71 - Packaging and Transportation of Radioactive Material (10 CFR 71), January 2004.

3. Diggs, J.M., Pope, R. B., Trujillo, A. A. and Uncapher, W. L., "Crush Testing of Small Type B Packagings”, Sandia Report SAND83-1145, November, 1985.

4. Gelder, L. F., Smith, A. C., and Blanton, P. S., "General Purpose Fissile Packaging Prototype Tests”, Savannah River National Laboratory Report M-TRT-A-00006, November, 2004.

5. Gelder, L. F. and May, C. M., “9977 General Purpose Fissile Packaging Prototype Testing”, Savannah River National Laboratory Report M-TRT-A-00007, R.1, May 2006. 